\title{
DETECTION OF IMMUNOPEROXIDASE LABELLED MYCOPLASMAS IN CELL CULTURE BY LIGHT MICROSCOPY AND ELECTRONMICROSCOPY
}

\author{
D. Chasey and S. B. Woods
}

Central Veterinary Laboratory, New Haw, Weybridge, Surrey, KT15 3NB

\begin{abstract}
Summary. A McCoy cell line persistently infected with Mycoplasma orale was examined by light microscopy and electronmicroscopy after specific labelling with a direct immunoperoxidase conjugate. Mycoplasmas were readily detected in monolayer cultures in bright-field conditions and these were related to labelled organisms observed by electronmicroscopy in thin sections of similar cells. The specificity of the conjugate for $M$. orale was demonstrated by blocking with unconjugated antiserum, and by its inability to detect $M$. bovirhinis. Non-specific background labelling was consistently absent.
\end{abstract}

\section{INTRODUCTION}

The importance of mycoplasmas as contaminants of cell cultures has been recognised for many years (Hayflick, 1965). Contamination is common and frequently undetected because often it has no visible effect upon the cells. Even in such cases its presence is undesirable, especially for experimental procedures, because the use of contaminated cells may lead to false conclusions. The profound changes in cellular physiology that may result from such contamination and the wide variety of anomalies that may arise from those changes have been described by Stanbridge (1971; 1981), Schneider and Stanbridge (1975) and Hessling, Miller and Levy (1980).

Cultural techniques provide potentially the most sensitive method for the detection of mycoplasma contamination (Stanbridge and Katayama, 1978) but complex media are required, the procedure is time-consuming and the isolation of certain species commonly associated with cell culture sometimes poses particular problems. The most serious problem is the phenomenon of the so-called "non-cultivable" mycoplasmas. The term has been applied to strains of Mycoplasma hyorhinis growing in tissue culture that fail to grow on axenic media (Hopps et al., 1973; Hopps, Del Giudice and Barile, 1976; Del Giudice and Hopps, 1978; McGarrity, Sarama and Vanaman, 1979) but this characteristic is apparently not limited to $M$. hyorhinis because Furness and Whitescarver (1975) described a strain of $M$. hominis adapted to grow only in the presence of viable cells. Stanbridge and Schneider (1977) discussed the problems associated with the use of cultural methods for mycoplasma detection and put forward 
a case for the inclusion of both indirect (i.e., non-cultural) and cultural procedures in any testing programme.

Various techniques may be used as adjuncts or alternatives to culture. Of the serological methods, immunofluorescence techniques are the most sensitive (Stanbridge and Katayama, 1978). Direct and indirect immunofluorescence have been used successfully to demonstrate infection in cell culture. They have the disadvantage, in common with immunoperoxidase techniques, that, for routine screening purposes, multiple or polyvalent antisera must be used to detect all likely infecting mycoplasma species. Nevertheless these procedures may be effectively applied for specific purposes such as monitoring for the presence of "non-cultivable" $M$. hyorhinis.

Labelling of mycoplasmas with immunoperoxidase conjugates, followed by treatment with $3,3^{\prime}$ diaminobenzidine- $\mathrm{H}_{2} \mathrm{O}_{2}$, is an alternative to immunofluorescence (Polak-Vogelzang, Reygers and Hekkens, 1980) and enables infected cell cultures to be assessed under bright-field conditions. The immunolabelling technique is also applicable to electronmicroscopy (see Williams, 1977) and we have investigated its ability to detect $M$. orale in cultured monolayers using light microscopy and electronmicroscopy. In addition to its role in the detection of infection in cell culture, the immunoperoxidase technique effects specific ultrastructural labelling and should be a valuable technique for the study of mycoplasma-cell interactions.

\section{MATERIALS AND METHODS}

Mycoplasma orale was isolated from, and examined in, a McCoy cell subline found to be infected on receipt in this laboratory. Organisms were isolated in $\mathrm{C}$ medium (Olson, Kerr and Campbell, 1963), modified by inclusion of penicillin 1000 i.u./ml and supplemented with yeast extract, and, after cloning, were typed by growth inhibition tests.

Preparation of specific $M$. orale antiserum. Antigen was prepared as described by Thorns and Boughton (1980) and injected intravenously into rabbits; Freund's adjuvant was not used because it enhances only the production of antibodies to serum proteins without increasing the yield of those specific for mycoplasma antigens (Thorns and Boughton, 1980). Immunoglobulin was precipitated from the resulting serum with sodium sulphate and coupled to horseradish peroxidase (Sigma Type VI) by the method of Wilson and Nakane (1978). The conjugate was added, without purification, to an equal volume of glycerol and stored as a stock solution at $-20 \mathrm{C}$.

Cell cultures. The McCoy cell systems studied were the $M$. orale-infected subline, another subline of McCoy cells found by culture to be free of mycoplasmas, and the latter subline deliberately infected with $M$. bovirhinis. The cells were grown as monolayers either on glass coverslips or in 10-ml plastic Falcon flasks (Nunc, Denmark). Eagle's medium containing fetal calf serum $10 \%$ was used for cell growth and the same medium with serum $2 \%$ was used for cell maintenance.

Light microscopy. Confluent cultures on coverslips were fixed in acetone for $10 \mathrm{~min}$ and labelled directly by a method described previously (Chasey, 1980); after fixation, the coverslips were dried in air and covered with a 1 in 10 solution of the stock conjugate in $0.1 \mathrm{M}$ sodium phosphate buffer $\left(p \mathrm{H} \mathrm{7.3)}\right.$. The cells were incubated at $20^{\circ} \mathrm{C}$ in a humidified chamber for $30 \mathrm{~min}$ and rinsed briefly in phosphate buffer. Cell monolayers were covered with the enzyme substrate, 3,3' diaminobenzidine- $\mathrm{H}_{2} \mathrm{O}_{2}$, for $10-15 \mathrm{~min}$, rinsed briefly in distilled water and dried in air. Two control preparations were included: (i) $M$. orale-infected monolayers were exposed to unconjugated undiluted specific antiserum in a pre-incubation step before incubation with the conjugate, and (ii) the mycoplasma-free McCoy cells were grown and labelled in parallel with the $M$. orale-infected cultures. Additionally, M. bovirhinis-infected McCoy cells were labelled by identical procedures with the conjugated $M$. orale antiserum. All coverslips, some lightly counterstained with toluidine blue, were mounted in DPX and examined in bright-field conditions. 
Electronmicroscopy. Confluent $M$. orale-infected McCoy cultures in Falcon flasks were immunolabelled as follows. The medium was removed and, after rinsing briefly in $0.05 \mathrm{M}$

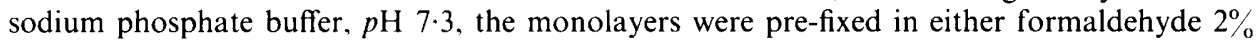
(paraformaldehyde solution $2 \% \mathrm{w} / \mathrm{v}$ ) for $1 \mathrm{~h}$ at $20 \mathrm{C}$ or a formaldehyde $2 \%$-glutaraldehyde $0.05 \%$ mixture for $5 \mathrm{~min}$. The cells were washed in one or two changes of the same buffer during $10 \mathrm{~min}$ and covered with $2 \mathrm{ml}$ of buffer containing approx. $15 \mu \mathrm{l}$ of the stock conjugate solution. The monolayers were incubated at $20^{\circ} \mathrm{C}$ for either $2 \mathrm{~h}$ or $17 \mathrm{~h}$ and the bottles were rocked gently during incubation. After washing in buffer for $1 \mathrm{~h}$, the cells were fixed in glutaraldehyde $3 \%$ for $5 \mathrm{~min}$, rinsed twice in buffer and covered with 3,3' diaminobenzidine- $\mathrm{H}_{2} \mathrm{O}_{2}$ solution for $10 \mathrm{~min}$. The cell sheets were rinsed twice in buffer, post-fixed in osmium tetroxide $1 \%$ for $1 \mathrm{~h}$ and dehydrated in several changes of ethanol. They were scraped from the plastic bottles and centrifuged to form pellets, before transfer to propylene oxide and conventional embedding in Araldite.

Thick sections, cut with glass knives, were stained with toluidine blue and mounted in DPX for bright-field examination by light microscopy. Thin sections, some counterstained with lead citrate and methanolic uranyl acetate, were examined in a Philips EM 300 electronmicroscope operating at $80 \mathrm{kV}$.

\section{RESULTS}

Cellular morphology of infected and non-infected coverslip cultures examined in bright field showed no unusual features, and the overall background was clear and free irom non-specific reaction product colour. However, conjugate-treated McCoy cultures infected with $M$. orale displayed dark brown granules distributed throughout the monolayers (fig. 1). The granules were often 'strung' together in clumps and, although clearly defined when examined with an oil immersion objective, were also easily discernible with a $\times 25$ objective lens. The disposition of granules in relation to individual cells was, generally, ill defined but occasional circular arrangements of labelled material indicated peripheral attachment to plasma membranes. Infected cultures immunolabelled after blocking pretreatment with unconjugated antiserum

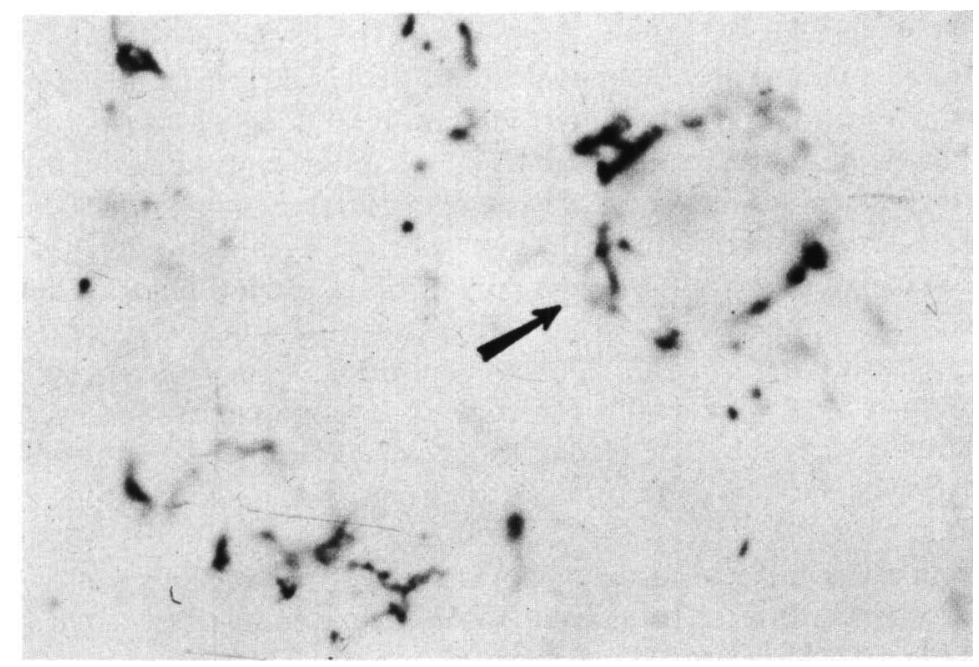

FIG. 1.- Monolayer culture of persistently infected McCoy cells viewed in bright field after specific immunolabelling for $M$. orale. The cells were not counterstained. Dense granules are prominent; a ring (arrow) of labelled organisms indicates peripheral attachment to an individual cell. $\times 1300$. 
showed a distinct reduction in the colour intensity of the labelled granules. Non-infected cultures and those infected with $M$. bovirhinis were free of this granular reaction product after treatment with the $M$. orale immunolabelling procedure. Thick sections of $M$. orale-infected cells also contained dense pleomorphic dark brown granules. Although not as numerous as in the coverslip preparations, a consequence mainly of sectioning, they were usually distributed on the surface of the cells. Many of the granules were apparently composed of several smaller particles forming a tight group (fig. 2).

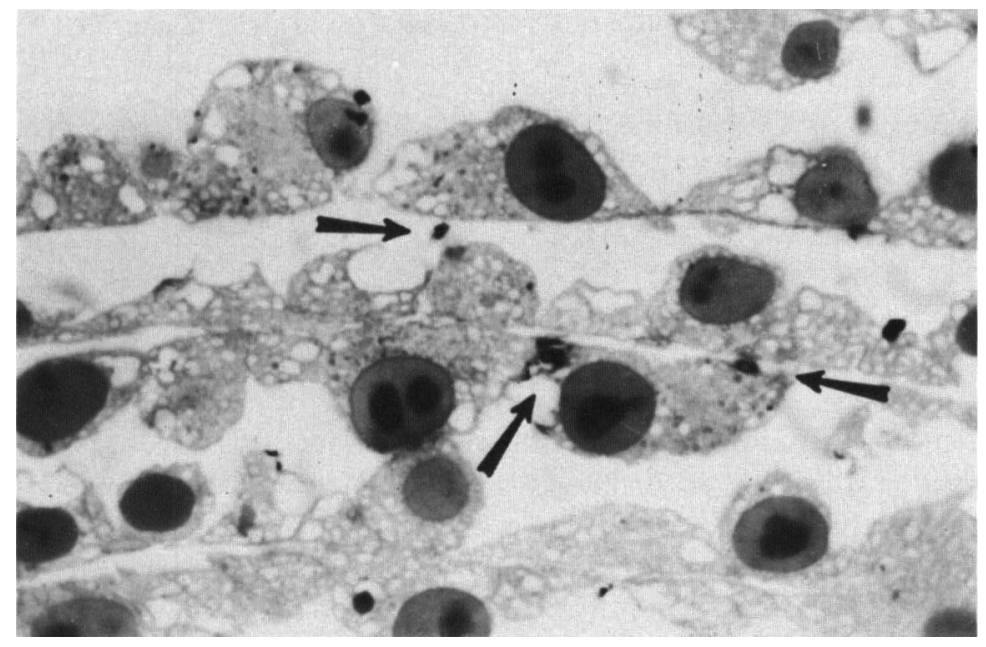

FIG. 2.-McCoy cell culture embedded in araldite after immunolabelling for $M$. orale. Groups of labelled mycoplasmas (arrows) are seen clearly. Thick section counterstained with toluidine blue. $\times 960$.

In thin sections examined by electronmicroscopy, intracellular vacuoles, also visible by light microscopy, were a feature of many cells and the morphology, in general, showed no unusual characteristics. However, ultrastructural quality was not optimal, as a result of the initial low-strength glutaraldehyde fixation necessary to maintain adequate specific antigenicity; many antigens studied by this type of immunocytochemical technique are destroyed or severely damaged by conventional fixation schedules and a compromise between satisfactory labelling and ultrastructural integrity is usually necessary. In these preparations, extracellular mycoplasma-like particles were seen, either singly or in groups, close or immediately adjacent to cell plasma membranes (figs. 3 and 4). These organisms were enveloped in electron-dense reaction product and were easily detected at low magnification, particularly in uncounterstained sections. The pleomorphic particles were present in spherical and filamentous forms and showed no intracytoplasmic labelling; reaction product was confined to their outer envelopes. Reaction product was also seen on host-cell membranes in areas adjacent to the mycoplasmas. This labelling, not confirmed by light microscopy because of insufficient resolution, was relatively light and evenly distributed (fig. 4). There was no evidence of surface labelling elsewhere, nor of any non-specific intracellular reaction product.

A few immunolabelled organisms were found intracellularly within the cytoplasm 


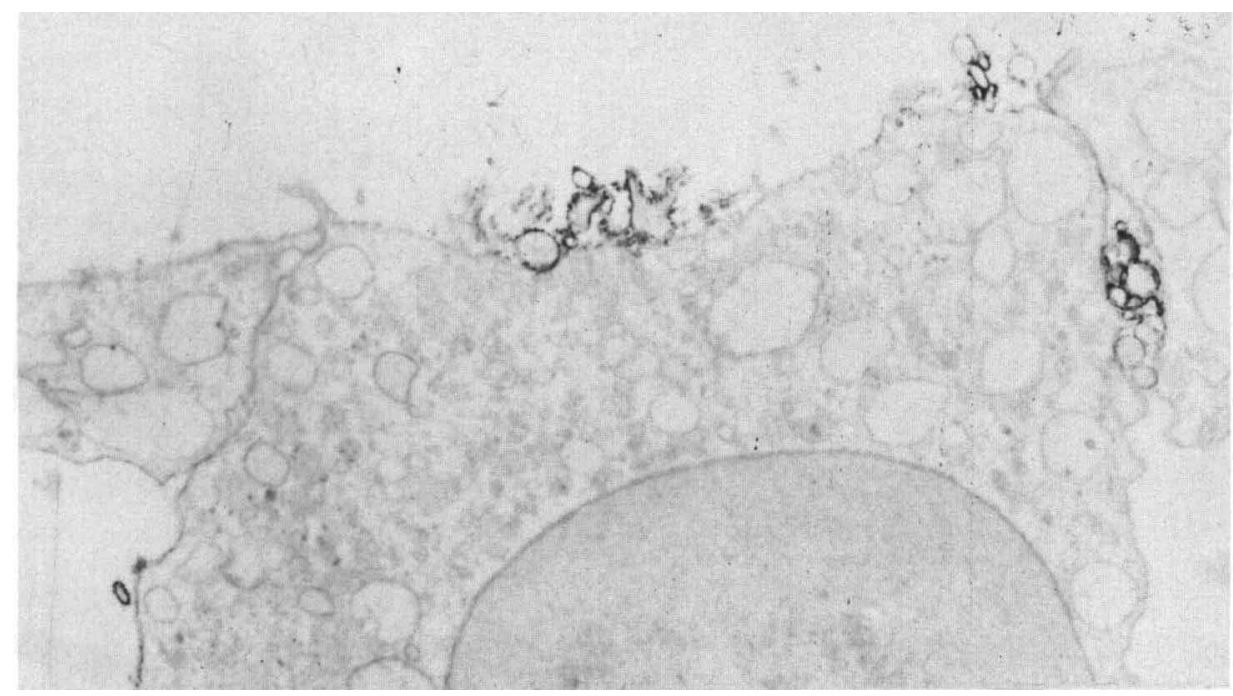

Fig. 3.-M. orale immunolabelled McCoy cells without counterstain examined by thin section electronmicroscopy. The cells were free from background reaction product. Individual specifically labelled organisms are visible adjacent to cell plasma membranes. $\times 9000$.

of a small proportion of the sectioned cells. These particles might otherwise have been mistaken for small vacuoles, but were generally similar in size and shape to the extracellular organisms and were clearly delineated by the reaction product on their surface. Intracellular labelled groups of particles were small and usually no more than three or four organisms could be identified (fig. 5).

\section{Discussion}

The ability of immunoenzymatic methods to detect specific antigens in cell culture

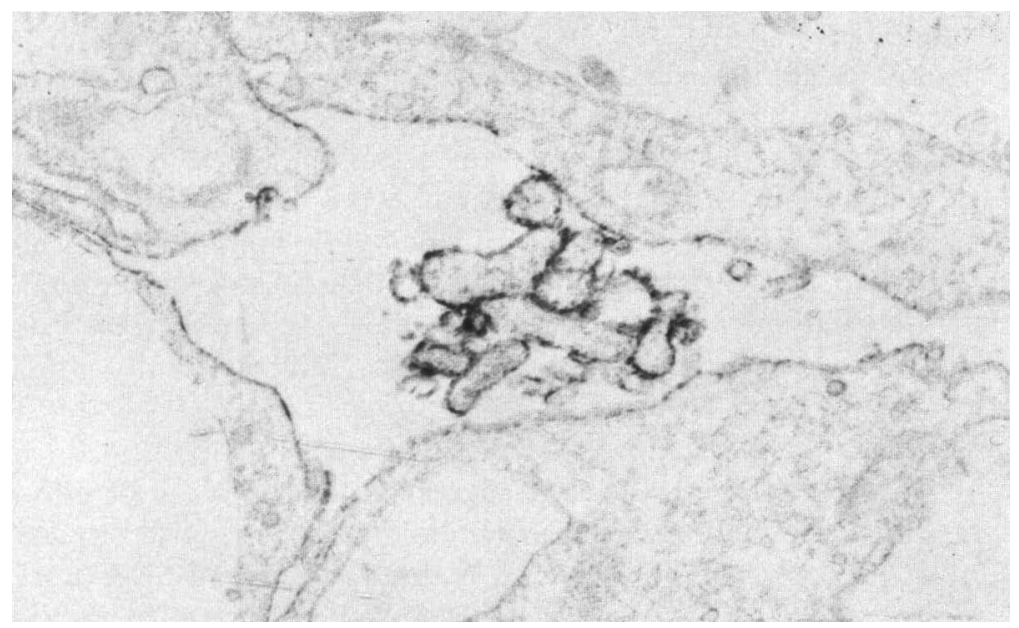

FIG. 4.-M. orale immunolabelled McCoy cells examined by thin section electronmicroscopy illustrating a group of labelled filamentous mycoplasmas. Light reaction product is also present on adjacent cell plasma membranes. Uranyl acetate and lead citrate counterstain. $\times 20000$. 


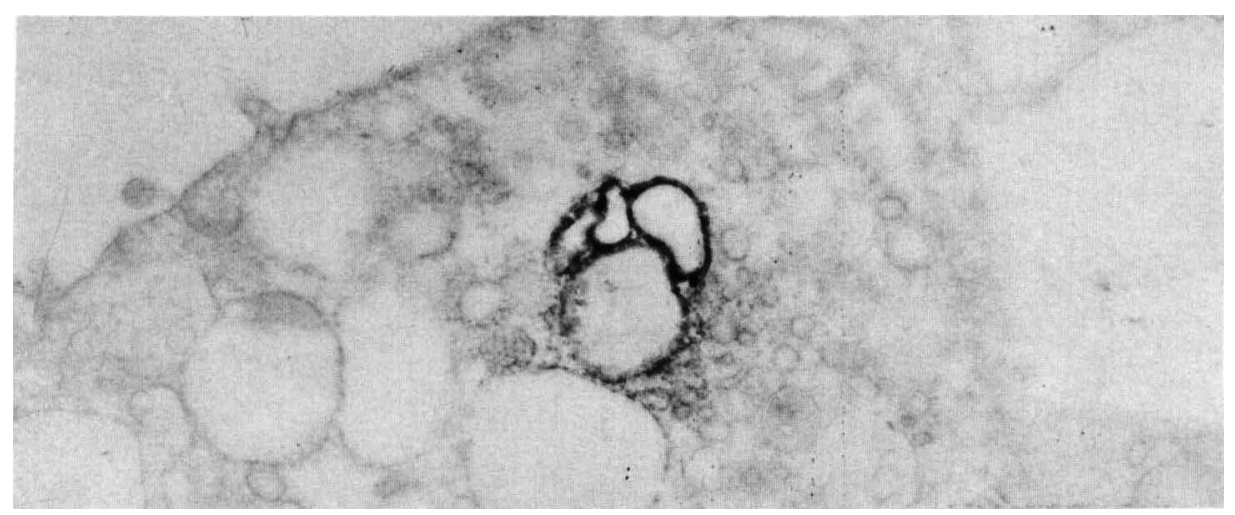

FIG. 5.- $M$, orale immunolabelled McCoy cells, without counterstain, examined by thin section electronmicroscopy illustrating a small group of intracellular labelled organisms. $\times 24000$.

and tissue has recently been demonstrated and such techniques, particularly the immunoperoxidase method, are being used increasingly either to complement or to replace immunofluorescence. The methods and applications of these techniques were discussed by Kurstak and Morriset (1974), Williams (1977), Heyderman (1979) and Mukai and Rosai (1980). In the present study a specific immunoperoxidase conjugate was applied successfully to localise $M$. orale in persistently infected cell cultures. By this method, organisms were visualised readily in mounted monolayer cultures at low magnification and general non-specific background colour was minimal. Groups of mycoplasmas were also detected easily in thick sections of similarly-labelled cells embedded in Araldite, and such groups were resolved into individual organisms in electronmicroscope preparations examined in parallel. Importantly, this comparison enabled the labelled granules seen by light microscopy to be identified specifically with morphologically distinct organisms, enabling more confident interpretation of granules seen in bright-field conditions as mycoplasmas. The detection of other Mycoplasma species should also be possible by immunoperoxidase-labelling methods using the appropriate conjugated specific antiserum. This technique offers an alternative to immunofluorescence, with which it shares the problem, however, that the presence of organisms in very small numbers might present difficulties in interpretation. Specific advantages of an immunoenzyme technique are the ease of visualisation in bright-field conditions, without the need for a UV microscope, and a generally improved picture of cell architecture compared with immunofluorescence preparations. In our experience with these methods, non-specific background colour is less of a problem than with fluorescent antibody labelling. In addition, the preparations are permanent and easily photographed, and the method is also applicable to electronmicroscopy.

The application of immunoperoxidase techniques to sections of frozen or paraffin-embedded material infected with mycoplasmas has yet to be fully assessed. However, an indirect immunoperoxidase method has been reported to demonstrate the presence of mycoplasmas in rats with naturally-occurring respiratory disease; specific labelling was detected in paraffin-embedded lung tissue and in nasopharyngeal and conjunctival swabs (Hill, 1978).

The absence of non-specific background colour in cultures examined by light 
microscopy was also noted in the thin-section electronmicrographs. Cell plasma membranes were generally free of any reaction product and their light labelling in the immediate vicinity of mycoplasmas (fig. 4) is, therefore, interesting; if labelling indicates the presence of specific mycoplasma antigens, this observation supports the view that organism and host can exchange membrane components (Razin et al., 1981). The distinctive labelling of intracytoplasmic organisms clearly confirms their existence within host cells, as seen previously with $M$. orale-infected McCoy cells examined conventionally by electronmicroscopy (Chasey, unpublished observations). The question of whether this represents mycoplasma survival or multiplication of ingested mycoplasmas within these cells has yet to be answered and requires further investigation. Electronmicroscopy and associated immunocytochemical techniques have a particular role in this context and in the study of the interaction between mycoplasmas and host cell membranes.

The combined use of light microscopy and electronmicroscopy with immunoperoxidase labelling is appropriate for experimental studies on mycoplasma infection, but bright-field microscopy alone could be usefully applied to routine detection of mycoplasma contamination. The use of $M$. orale as a model has shown that the direct labelling technique can be a helpful adjunct to conventional methods for identification. Although less sensitive for most Mycoplasma species than available cultural methods, immunoperoxidase labelling should assist considerably in the detection of fastidious mycoplasmas, such as the "non-cultivable" strains of $M$. hyorhinis which are widely recognised and important contaminants in cell culture systems.

We thank Mr A. D. Maley, Mrs A. Phillips and Miss. M. Emmerson for technical assistance.

\section{REFERENCES}

Chasey D 1980 A simple and rapid immunoperoxidase test for the detection of virus antigens in tissue culture. Veterinary Record 106:506-507.

Del Giudice R A, Hopps H E 1978 Microbiological methods and fluorescent microscopy for the direct demonstration of mycoplasma infection of cell cultures. In: McGarrity G J et al. (eds) Mycoplasma infection of cell cultures. Plenum Press, New York, p 57-69.

Furness G, Whitescarver J 1975 Adaptation of Mycoplasma hominis to an obligate parasitic existence in monkey kidney cell culture (BSC-1). Proceedings of the Society for Experimental Biology and Medicine 149:427-432.

Hayflick L 1965 Tissue cultures and mycoplasmas. Texas Reports on Biology and Medicine 23: Suppl. 1, 285-303.

Hessling J J, Miller S E, Levy N L 1980 A direct comparison of procedures for the detection of mycoplasma in tissue culture. Journal of Immunological Methods 38:315-324.

Heyderman E 1979 Immunoperoxidase technique in histopathology: applications, methods, and controls. Journal of Clinical Pathology 32:971-978.

Hill A C 1978 Demonstration of mycoplasmas in tissue by the immunoperoxidase technique. Journal of Infectious Diseases 137:152-154.

Hopps H E, Del Giudice R A, Barile M F 1976 Current status of "non-cultivable" mycoplasmas. Proceedings of the Society for General Microbiology 3:143.

Hopps H E, Meyer B C, Barile M F, Del Giudice R A 1973 Problems concerning "non cultivable" mycoplasma contaminants in tissue cultures. Annals of the New York Academy of Sciences 225:265-276.

Kurstak E, Morisset R 1974 Viral immunodiagnosis, Section 1; Immunoenzymatic techniques in virology and viral oncology. Academic Press, New York, p 3-138.

McGarrity G J, Sarama J, Vanaman V 1979 Factors influencing microbiological assay of cell-culture mycoplasmas. In vitro. 15:73-81. 
Mukai K, Rosai J, 1980 Applications of immunoperoxidase techniques in surgical pathology. In: Fenoglio C M, Wolff M. (eds) Progress in surgical pathology, vol. 1. Masson Publishing USA, New York, p 15-49.

Olson N O, Kerr, K M, Campbell A 1963 Control of infectious synovitis. 12. Preparation of an agglutination test antigen. Avian Diseases 7:310-317.

Polak-Vogelzang A A, Reygers R, Hekkens F E N 1980 Isolation of Mycoplasma hyorhinis and Mycoplasma fermentans from cell cultures. Journal of Biological Standardization 8:243-254

Razin S, Kahane I, Banai M, Bredt W 1981 Adhesion of mycoplasmas to eukaryotic cells. In: Adhesion and microorganism pathogenicity. Ciba Foundation Symposium No. 80, Pitman Medical, Tunbridge Wells, p 98-118.

Schneider E L, Stanbridge E J 1975 Comparison of methods for the detection of mycoplasmal contamination of cell cultures: a review. In vitro. 11:20-34.

Stanbridge E J 1971 Mycoplasmas and cell cultures. Bacteriological Reviews 35:206-227.

Stanbridge E J 1981 Mycoplasma detection - an obligation to scientific accuracy. Israeli Journal of Medical Science 17:563-568.

Stanbridge E J, Katayama C 1978 Principles of morphological and biochemical methods for the detection of mycoplasma contaminants of cell cultures. In: McGarrity G J et al. (ed) Mycoplasma infection of cell culture. Plenum Press, New York, p 71-86.

Stanbridge E J, Schneider E L 1977 The need for non-cultivable methods for the detection of mycoplasma contaminants. Developments in Biological Standardization 37:191-200.

Thorns C J, Boughton E 1980 Studies on the effect of growth medium composition on the antigenicity of Mycoplasma bovis. Journal of Hygiene (Cambridge) 84:29-36.

Williams M A 1977 Immunocytochemistry at the EM level: staining antigens with electrondense reagents. In: Glauert A M (ed) Practical methods in electron microscopy, vol 6. North Holland Publishing Co., Amsterdam, p 41-76.

Wilson M B, Nakane, P K 1978 Recent developments in the periodate method of conjugating horseradish peroxidase (HRPO) to antibodies. In: Knapp W, Holubar K, Wicks G. (eds) Immunofluorescence and related staining techniques. Elsevier/North Holland Biomedical Press, Amsterdam, p 215-224. 